\title{
Mapping the Potentials of Monster Studies
}

Ildikó Limpár

https://doi.org/10.30608/HJEAS/2021/27/1/14

\section{Weinstock, Jeffrey Andrew, ed. The Monster Theory Reader. University of Minnesota Press, 2020. ix + 560 pages + 33 b\&w photos. ISBN 978-1-5179-0525-5. \$35.00. Pbk.}

Jeffery Jerome Cohen's 1996 seminal essay, "Monster Culture," marks the beginning of modern monster studies as a separate sub-discipline, which since then has produced an immense amount of valuable material in the form of journal articles, monographs, and anthologies specialized in a segment of teratology. Therefore, compiling an anthology of essential theoretical texts for those who study the field is a welcome addition. Jeffrey Andrew Weinstock undertook this task of no little importance and difficulty, and the result is "monstrously" impressive: the nearly 600-page-long collection of theory may look threatening to many, but it definitely provokes awe as it invites the curious reader on a fascinating journey to map the potential of monster studies.

Providing the reader with the genealogy of monster theory, Weinstock first looks at early conceptions concerning monstrosity and offers a brief historical overview of humans' relations to monsters and successfully paves the way to the chapters that follow. Closing this section with explaining the significance of Michel Foucault's work in positioning the monster as a socially constructed category is crucial because no text by Foucault is included otherwise in the collection. Weinstock's Introduction is then followed by Cohen's essay as a text in the light of which the whole volume should be read.

The volume is clearly structured, comprising four main parts. Of course, as monsters defy categorization, essays on monstrosity—due to their hybridity—at times prove equally 
difficult to be placed under the "correct" rubric; nevertheless, the placement of the articles in this collection is always justified. Part I, "Monster Theory Toolbox," collects six essays that introduce fundamental concepts and terminology and provide the background or clarification for Cohen's statements. As monster studies is rooted in the study of the psyche, justifiably, we find here Freud's "The Uncanny" and Kristeva's "Approaching Abjection," which are inevitable reference points in the field. Masahiro Mori's brief scientific article concerns robotic engineering and concentrates on the relationship between movement and uncanniness, interestingly completing Freud's thoughts on the uncanny. This essay, like several others in this volume, reveals the editor's strong ties with film studies (also evident in the next chapter), Robin Wood's “An Introduction to the American Horror Film.” While it is a must-read mostly for those who deal with horror films, the first half of the article is a more generally applicable theoretical exploration of the concept of the other. The last two essays in Part I elaborate on the hybridity of the monster that Cohen emphasizes. In his "Fantastic Biologies and the Structures of Horrific Imagery," Noël Carroll digs deeper into the ways various monsters transgress boundaries and clarifies the processes through which monsters are formed. Jack Halberstam's often cited essay "Parasites and Perverts: An Introduction to Gothic Monstrosity" (originally published under the pen name Judith Halberstam) concludes this section, shifting the focus from appearance to meaning. Halberstam underlines the connection between monster studies and Gothic studies via exploring how Gothic texts as well as monsters themselves reject their presenting or embodying one exclusive meaning, arguing that the horror in Gothic novels - especially embodied horror as monstrosity-comes from the impossibility of determining one explicit meaning.

The essays that Part II, "Monsterizing Difference," features provide insight into how monsterization may become an effective political tool to stigmatize groups of people based on any kind of deviance from the normative-let it be somatic, racial, religious or sexual. The 
first two essays in this section explore the historical dimension of monsterizing people: Alexa Wright's study highlights the significance of the Monstrous Races, a drawing in the late twelfth-century Arnstein Bible, as the reflection of the observer's approach concerning "the human monster as the embodiment of social, moral, or ontological disorder" (179) that has had a lasting influence on mankind's imagination concerning otherness. While the drawing Wright discusses places emphasis on the deviance of the body, the next chapter, by Bettina Bildhauer, accentuates the ways in which a group of people-Jews in this case-may easily be monsterized even if they are not marked by a non-normative physique. The monsterization of women is in the focus of Barbara Creed's seminal essay, entitled "Horror and the Monstrous-Feminine: An Imaginary Abjection." This paper could easily belong to the toolbox section as well, since its profound analysis is indispensable to all monster studies scholars and not only to those who do research on filmic horror (even though the paper examines how the monstrous feminine appears on the screen). While femininity and thus one's sex are the focal concepts from which Creed's discussion stems, Harry Benshoff's chapter-a contribution again from the discipline of film studies-revolves around how queerness/homosexuality is connected, often via subtle means, to monstrosity. This study is followed by two papers that revisit the major themes of physical deviance and race. Annalee Newitz's "The Undead: A Haunted Whiteness" reveals that the tendency to monsterize others is deeply embedded in the practice of colonization and the institution of slavery and is now perceivable in associating racial others with undead monsters, while in "Intolerable Ambiguity: Freaks as/at the Limit," Elizabeth Grosz scrutinizes our relationship to somatic freakery and prepares the way to Part III, in which monstrosity as a culturally ingrained category is considered.

"Monsters and Culture" (Part III) aims to provide a composite picture of the ways monstrosity reflects social beliefs and norms. The first two essays observe the moral context 
of monsters. Whereas Stephen T. Asma's "Monsters and the Moral Imagination" introduces how representatives of the Other inform us of the socially acceptable norm in moral questions, Timothy Beal briefly discusses the paradoxical representation of monstrosity in a religious context, where the monstrous may be a tool of demonizing as well as deifying. Margrit Shildrick's “The Self's Clean and Proper Body," in its title resonates with the themes of the previous two papers. Her use of the words "clean" and "proper" evoke the concepts of morality and religion even though primarily these terms were related to Kristeva's concept of the abject. As the chapter investigates the interrelations of body, subjecthood, and identity of the clinical other, most notably in the cases of conjoined twins; however, it becomes evident that the corporeal and the ontological considerations are inseparable from the ethical ones. The next cultural topic that monsters are coupled with is nostalgia (and with that, modernity) in Michael Dylan Foster's illuminating essay on tanuki-related folklore. "Haunting Modernity: Tanuki, Trains, and Transformation in Japan" is a thorough investigation of how modernization, emblematically embodied by the railway, has brought about new folklore that reflects on people's relationship to nature and the transformation that they experience or wish for in their lives. Foster's research thought-provokingly demonstrates Cohen's first thesis that renders monsters cultural signifiers. This idea is also approached from the perspective of film studies by the editor of the volume, Weinstock, who looks at the variations of the monster that is "reconfigured as a kind of invisible disease that eats away at the body and the body politic and manifests visibly through symptomatic behavior" (359). Finally, this part offers two chapters where current political issues provide the cultural context in which the process of monsterization is dissected. Jasbir K. Puar and Amit S. Rai posit gender and sexuality as instrumental in depicting the terrorist as the embodiment of the monstrous, while Jon Stratton presents the zombie as the monster that signifies "bare life," understood in our contemporary reality as the life of "displaced people" (403). 
Studies that seek hope beyond the fear and the desire that monsters usually embody close the volume, collected in Part IV. "Beasts from the Deep" by Erin Suzuki compares three films in which the deep waters of the Pacific and battles with aliens play a central role. Suzuki points out the moments of hope that these productions hold up to the audience either in the form of uniting mankind (despite their political opposition) against the alien monster or in the possible recognition that humanity is being shaped by its environment. The monster and its capacity to communicate about our natural environment stands in the center of Anthony Lioi's discussion of the swamp dragon - the monster by which one may "consciously construct a symbolic place in ecocriticism for dirt and pollution," which may thus be considered "an alias or icon that allows us to give dirt its due" (439). Further analyzing the challenges of environmentalism, Donna Haraway deconstructs the binarism we apply to understand nature that she redefines as "a co-construction among humans and non-humans" (462). In "The Promises of Monsters," the essay from which Part IV borrowed its title, Haraway examines the promises or hopes "inappropriate/d others" hold, and urges us to build new collectives. The potential of such a co-construction emphasizes the importance of "borderlands" (506). Finally, Patricia MacCormack's "Posthuman Teratology" explores the borderland that the hybrid posthuman subject inhabits as the site for the expansion of human possibilities and potentials.

Such collections rarely give a full picture of a discipline; I, for instance, would have welcomed a contribution on plant horror in the toolbox or culture section, not only because plant studies is an often overlooked segment of monster studies, but also because it would have formed an interesting dialogue with the essays in Part IV that put emphasis on the new perspective about nature and environmentalism. Yet, what could not be included is acknowledged in the form of a further reading section, thus this interdisciplinary collection amply serves its purpose: it celebrates monster studies as an established branch of scholarship 
and points out the multiple ways monsters allow us to make sense of our reality. While some chapters (Kristeva, Haraway, McCormack) may be too difficult for undergraduate students to work with, most of the essays have a reader-friendly language and structure. The Monster Theory Reader provides an essential guide for those who wish to study the monstrous; therefore, this anthology may be a valuable and useful addition to any college or university library.

Pázmány Péter Catholic University, Budapest 